\title{
GASTRO RETENTIVE DRUG DELIVERY SYSTEMS: A REVIEW
}

\author{
Sai Dividevara*, K. Naveen Kumar and K. Preethi \\ Vignan Pharmacy College, Vadlamudi, \\ Guntur, Andhra Pradesh, India.
}

\begin{abstract}
In the current days, gastro retentive drug delivery systems (GRDDS) receive the great attention because they increase the performance of controlled release dosage forms, which can take orally. It is a widely employed technique to retain the dosage form in the stomach for a long period by releasing the drug slowly. These systems improved the patient compliance, which increases the therapeutic index of drugs. Various physiological barriers associated with the gastro retentive drug delivery systems such as short gastric retentive time, variation in gastric emptying time that can reduced by this technique. To formulate GRDDS various approaches like floating drug delivery systems, non-effervescent drug delivery systems, high density drug delivery systems, bioadhesive systems, magnetic systems, expandable systems etc.,. The present review mainly focuses on the requirements for formulating the GRDDS, various approaches involved in formulation and factors affecting gastric residence time.
\end{abstract}

Keywords: Gastro retentive drug delivery system (GRDDS) and Physiological barriers.

\section{INTRODUCTION}

Despite significant advancements in drug delivery, technology oral route is the most preferred route of administration for various active ingredients due to case administration, low cost drug, patient compliance, flexibility design of formulation ${ }^{1,2}$. Orally administered conventional dosage forms do not have proper controlled over drug release and lead to high fluctuations in plasma drug concentration. However many drugs absorbed from specific sites and they require release at the particular site for better absorption. So the controlled release drug delivery systems has formulated to release the specific amount of the drug at particular site 4 . Controlled release drug delivery system widely employed due to various advantages like enhanced therapeutic action with in case in the duration of drug release and improves the bioavailability.

Gastro retentive drug delivery system are one of the type of controlled release drug delivery systems they can retain in the gastro intestinal region for a long period of time and altering the gastric emptying time and motility pattern of GIT $^{5}$.GRDDS are feasible for drugs that having low absorption in the lower part of GIT. Unstable, and poorly soluble at alkaline $\mathrm{p}^{\mathrm{H}}$ and the drugs having shorter half-life ${ }^{6,7}$. Various formulation related factors such as polymer types (non-cationic, anionic) polymer, composition, viscosity, molecular weight of polymer and drug solubility can effect the quality of the gastro retentive dosage form ${ }^{8}$.

The stomach is a J-shaped enlargement of the Gl tract directly inferior to the diaphragm in the abdomen. The stomach connects the oesophagus to the duodenum, the first part of the small intestine.

\section{ANATOMY OF THE STOMACH}

The stomach has four main regions: the cardia, fundus, body and pyloric part. The cardiac surrounds the superior opening of the stomach. The rounded portion superior to and to the left of the cardia is the fundus. Inferior to the fundus is the large central portion of the stomach, the body. The pyloric part is divisible into three regions. The first region, the pyloric antrum, connects to the body of the stomach. 
The second region, the pyloric canal, leads to the third region, the pylorus, which in turn connects to the duodenum. When the stomach is empty, the mucosa lies in large folds, or rugae, that can be seen with the unaided eye. The pylorus communicates with the duodenum of the small intestine via a smooth muscle sphincter called the pyloric sphincter. The concave medial border of the stomach is lesser curvature; the convex lateral border is greater curvature $^{9}$ (Fig. 1: Anatomy of stomach).

\section{FUNCTIONS OF STOMACH}

The functions of the stomach include the following ${ }^{10}$

1) Temporary storage allowing time for the digestive enzymes, pepsins, to act

2) Chemical digestion -pepsins break proteins into polypeptides.

3) Mechanical breakdown- the three smooth muscle layers enable the stomach to act as a churn, gastric juice has added and the contents are liquified to chime. Gastric motility and secretion has increased by parasympathetic nerve stimulation.

4) Limits absorption- water, alcohol and some lipid soluble drugs.

5) Non-specific defence against microbes- provided by hydrolytic acid in gastric juice. Vomiting may occur in response to ingestion of gastric irritants, e.g. microbes or chemicals.

6) Preparation of iron for absorption- the acid environment of the stomach solubilises iron salts, essential for iron absorption in the small intestine.

7) Production and secretion of intrinsic factor needed for absorption of vitamin $B_{12}$ in the terminal ileum.

8) Regulation of the passage of gastric contents into the duodenum. When the chyme is sufficiently acidified and liquefied, the pylorus forces small jets of gastric contents through the pyloric sphincter in the duodenum. The sphincter is normally closed, preventing, backflow of chime into the stomach.

\section{ADVANTAGES OF GRDS}

The advantages ${ }^{11}$ regarding gastro retentive drug delivery system includes

$\checkmark$ It has been using in the treatment of peptic ulcer disease.

$\checkmark$ Commonly used for drug having narrow therapeutic index. To minimize the dosing frequency.

$\checkmark$ Improved bioavailability of drugs. $\checkmark$ Used for drugs which are normally unstable in intestinal fluids.

$\checkmark$ Used to provide sustained delivery for the drugs used for maintaining maximum therapeutic drug concentration within the therapeutic withdraw.

\section{DISADVANTAGES OF GRDDS}

Although there are advantages, this also

having disadvantages ${ }^{12,13}$. They are

$\checkmark$ Drugs that are unstable in high acidic environment, very low solubility in acid environment causes irritation to gastric mucosa and cannot formulated as GRDDS.

$\checkmark$ FDDS (Floating Drug Delivery Systems) require high level of fluid in stomach for floating and working more efficiently. So more water intake has needed with such dosage form.

\section{FACTORS AFFECTING GRDDS}

\section{Density}

The density of the dosage form should be less than that of the gastric contents $(1.004 \mathrm{~g} / \mathrm{ml})$.

\section{Size}

Dosage form having diameter of more than $7.5 \mathrm{~mm}$ have more gastric residence time than that of $9.9 \mathrm{~mm}$ diameter dosage form ${ }^{14}$.

\section{Shape of the dosage form}

A diameter resided in the stomach for a longer period than other devices of similar size. The single or multiple unit formulation -multiple unit formulation show a greater predictable release profile and insignificant impairing of the performance due to failure of the units with different release profile or containing incompatible substances and permit larger margin of safety against dosage form failure compared with single unit dosage form.

\section{Fed or unfed state}

Under fasting conditions, the GI motility has characterized by periods of strong motor activity that occurs every 1.5-2 hrs. The MMC (Migrating Motor Complex) sweeps undigested material form the stomach and if the timing of the formulation coincides with that of MMC, the GRT of the unit can be very short, however in fast state MMC is delayed and GRT is longer ${ }^{15}$.

\section{Nature of meal}

Feeding of indigestible polymers or fatty acids can change the motility pattern of the stomach to a fed state, thus decreasing gastric emptying, rate and prolonging drug release.

\section{Caloric content}


GRT can increased by $4-10$ hours with a meal that is high in protein and fat.

\section{Frequency the meal}

Feeding increase over 400 min when successive meals given are compared with the single meal due to low frequency of $M M C^{16,17}$.

\section{Gender}

Mean ambulatory GRT in male $(3,4 \mathrm{hrs})$ is less compared with the age and race matched female counterparts $(4,6 \mathrm{hrs})$ regardless of height, weight and body surface ${ }^{18}$.

\section{Age}

People with age more than 70 have a significant longer GRT.

\section{Concomitant drug administration}

Anti-cholinergic like atropine and propantheline, opiates like codeine can prolong $\mathrm{GRT}^{19}$.

\section{REQUIREMENTS FOR GASTRO \\ RETENTIVE FORMULATION}

The requirements for formulating a GRDS, it include ${ }^{11}$

1) Drugs that act locally in stomach (antacids and drugs for H. Pyloric viz., Misoprostol)

2) Drugs those are primarily absorbed in the stomach (Amoxicillin)

3) Drugs that is poorly soluble at intestinal fluids (Furosemide, Diazepam, Verapamil)

4) Drugs which show a narrow window (Cyclosporine, Methotrexate, Levodopa)

5) Drugs that are absorbed rapidly in the Gl tract (Metronidazole, Tetracycline)

6) Drugs that usually degrade in the colon (Ranitidine, Metformin $\mathrm{HCl}$ )

7) Drugs that disorganize normal colonic microbes (Antibiotics against Helicobacter pylori)

\section{COMMONLY USED DRUG IN FORMULATION OF GRDDS}

The drugs, which satisfies the above requirements, can only formulated as gastro retentive drug delivery systems. Some of the examples of drugs has discussed in Table 1 and commercially available marketed products has discussed in Table 2 respectively ${ }^{20,21}$.

\section{APPROACHES FOR GASTRO RETENTIVE DRUG DELIVERY SYSTEM}

There are various approaches for formulating the gastro retentive drug delivery systems. Some of the methods has depicted in Figure 2.

\section{Non-floating drug delivery systems \\ a. High density (sinking) drug delivery system \\ The density of the formulation exceeds the} density of the normal gastric content. The materials increase the density up to 1.5-2.4 $\mathrm{gm} / \mathrm{cm}^{3}$. Depending on the density, the GI transit time of pellets can be extended from an average of 5.8-24 hours. But the effectiveness of this system in human beings was not observed and no formulation has been marketed $^{22}$.

\section{b. Bioadhesive or mucoadhesive drug delivery system}

The gastric retention time has extended by adhering the bioadhesive system for gastric mucous membrane.The adherence of the delivery system to the gastric wall increases residence time thereby improving bioavailability. The chemicals used for the mucoadhesion purpose include polycarbophil, carbopol, lecithin, chitosan, carboxy methylcellulose, gliadin etc., ${ }^{23}$. Novel adhesive material derived from fimbrae of bacteria or its synthetic analogues have also been tried for the attachment to the gut. However, the gastric mucoadhesive force does not tend to be strong enough to resist the propulsion force of the stomach wall. The continuous production of mucus and dilution of the gastric content is another limitation for such type of system. Many investigators have tried out a synergestic approach between floating and bioadhesion system (Fig. 3: Mucoadhesive drug delivery system).

\section{c. Magnetic system}

In this system, the dosage form contains a small magnet and another magnet is placed on the abdomen over the position of the stomach. The external magnet should be placed with a degree of precision which may decrease the patient compliance.

\section{d. Expandable System}

These systems are capable of expanding and retain in the stomach for longer periods. These are usually formulated as a capsule containing dosage form folded and compact form. After being exposed to stomach environment, capsule shell disintegrates and dosage form expands preventing its exit through the stomach. By using a suitable polymer, sustained and controlled drug delivery can be achieved. 


\section{Floating Drug Delivery System}

\section{a. Effervescent System}

These systems was further classified into

\section{i) Gas generating System}

The main mechanism is involved in this system is the production of $\mathrm{CO} 2$ gas due to reaction between sodium bicarbonate, citric acid and tartaric acid. The gas produced results in the reduction of density of the system, thereby making it float on the gastric fluids. Salts and citric/tartaric acid release $\mathrm{CO} 2$, which entrapped in the jellified hydrocolloid layer of the system which decrease its specific gravity and making it float over chime ${ }^{24}$. The system consist of a sustain release pill as seed surrounded by double layer. The inner layer is an effervescent layer containing sodium bi carbonate and tartaric acid. The outer layer is of a swellable membrane layer containing PVA shellac. (Fig. 4: Effervescent drug delivery system)

\section{ii) Volatile liquid containing system}

These have an inflatable chamber which contains a liquid e.g. ether, cyclopentane, that gasify at body temperature to cause the inflation of the chamber in the stomach. These systems osmotically control floating system containing a hollow definable unit. These are two chambers in the system first contain the drug and the second chamber containing the volatile system.

These systems has again classified into following

\section{$\checkmark$ Intra gastric floating gastrointestinal drug delivery system}

This system contains a floatation chamber which contains vacuum or an inert, harmless gas and a micro porous compartment enclosing drug reservoir.

\section{$\checkmark$ Inflatable gastrointestinal drug delivery system}

These systems possess inflatable chamber containing liquid ether which gasifiers at body temperature to inflate the stomach. Inflatable chamber contains bio erodible polymer filament (e.g Copolymer of poly vinyl alcohol and poly ethylene) that gradually dissolves in gastric fluid and finally cause an inflatable chamber to release gas and collapse. $\checkmark$ Intra-gastric osmotically controlled drug delivery system

It is composed of osmotic pressure controlled drug delivery device and an inflatable floating capsule.in the stomach, inflatable capsule disintegrates and release the osmotically controlled drug delivery system which contains two components: drug reservoir compartment and osmotically active compartment. Superporous hydrogels are an excellent example, working on this approach. The dosage form swells significantly to several times of original volume upon contact with gastric fluid, the gastric contraction pushes the dosage form to the pylorus but due to the larger size of the dosage form, the contractions slips over the surface of the system, due to which the dosage form pushes back into the stomach.

\section{b. Non-effervescent systems}

Non-effervescent system can be further divided in to hydro dynamically balanced system, Microbaloons, alginate beads and microporous compartment ${ }^{25}$.

i. Hydrodynamically balanced system It is a formulation of a drug with gel forming hydrocolloids meant to remain buoyant in the stomach contents .Drug Delivery Systems have a bulk density lower than gastric fluids and thus remain buoyant in the stomach for a prolonged period of time, without affecting the gastric emptying rate. While the system is floating on the gastric contents, the drug is released slowly at a desired rate from the system. After the release slowly at a desired rate from the system. After the release of the drug, the residual system is emptified from the stomach. The results in an increase in the GRT and a better control of fluctuations in the plasma drug concentrations.

\section{ii. Micro balloons}

Micro balloons (Hollow microsphere) are in the strict sense, empty particles of spherical shape without core. These microspheres are characteristically free flowing powders comprising of proteins or synthetic polymers, ideally having a size less than 200 micrometres. Micro balloons loaded with drug in their outer polymer shell are prepared by a novel methods such as solvent evaporation to create a hollow inner core. the drug and an enteric acrylic polymer mixture are dissolved in ethanol /dichloromethane solution and it is 
poured into an agitated solution of Poly Vinyl Alcohol (PVA) that as thermally controlled at $40^{\circ} \mathrm{C}$. After the formation of stable emulsion, the organic solvent is evaporated from the emulsion by increasing the temperature under pressure or by continuous stirring. The gas phase is generated in the droplet of dispersed polymer by the evaporation of dichloromethane and thus formed the hollow internal cavity in the microsphere of the polymer with drugs.

\section{iii. Microporous compartment}

In this system, drug reservoir is encapsulated inside a microporous compartment having pores along its top and bottom walls. The floatation chamber containing entrapped air causes the delivery system to float over the gastric fluid enters through the aperture, dissolves the drug and carries the dissolved drug in the stomach and proximal part of the small intestine for absorption.

\section{iv. Alginate beads}

Freeze dried calcium alginates have been used to develop multi unit floating dosage forms ${ }^{26}$. By dropping sodium alginate solution into aqueous solution of calcium chloride spherical beads of about $2.5 \mathrm{~mm}$ diameter can be prepared. These beads are separated and air dried. This results in the formation of aporous system which remains buoyant in the stomach.

\section{EVALUATION}

1. Floating lag time (FLT), Total floating time (TFT) floating strength

For low-density system, raft-forming system

The test was carried out in a simulated fluid (SGF) at $37^{\circ} \mathrm{C}$. The time between introduction of dosage form and its buoyancy on the SGF (FLT) and the time during which the dosage form remains buoyant (TFT) were measured. The floating strength is measured using specifically designed basket holder connected with analytical balance. The reduction of weight on the analytical balance over time determines the floating strength $^{27,28}$.

\section{Swelling studies}

For super porous hydrogel system, expandable system.

The test is carried out by placing the weighed amount of dosage form into the swelling medium $(0.01 \mathrm{~N} \mathrm{HCl})$ and weight, diameter, and length of swollen samples are measured at predetermined time point $^{29,30}$.

\section{Viscosity and rheology}

For raft-forming and mucoadhesion systems.

Viscosity of polymer affects the consistency of the dosage form upon contact ith the gastriv fluid, Brookfield/Ostwald's viscometer and texture analyzer are commonly used ${ }^{31}$.

\section{In vitro unfolding study}

For expandable system.

The test is carried out by placing the folded dosage form into the dissolution medium and examining its unfolding behaviour in different time interval ${ }^{32}$.

5. Particle size, ion exchange capacity, moisture content

For ion-exchange resin system.

Particle size analysis has carried out using a sieve shaker; laser diffraction and coulter counter analyser. The ion exchange capacity depends upon the functional group available for cross-linking. Moisture content can be measured with Karl Fischer $^{33,34}$.

\section{General parameters}

a. In vitro drug release

The test is carried out in SGF at a predefined time interval (generally 0 12hrs)using USP type-II apparatus at 50 RPM and maintained at $37^{\circ} \mathrm{C}^{35,36}$.

\section{b. Gel strength}

The high gel strength is desirable for better mechanical integrity ${ }^{37}$.

\section{c. Drug - Excipient interaction study}

It can studied by using FT-IR spectroscopy, differential scanning calorimeter and high performance liquid chromatography ${ }^{38}$.

\section{CONCLUSION}

Based on the recent advancements it has concluded that gastro retentive drug delivery system is a promising approach for the drugs having poor bioavailability prior to their absorption is restricted particularly in upper gastro intestinal tract there by maximising their absorption and enhancing the bioavailability. Due to their maximum retention in gastric region, these formulations has majorly used in treatment of gastro intestinal diseases like gastritis and peptic ulcer. Commercially it is emerging slowly as an important novel drug 
delivery system with numerous potential benefits.

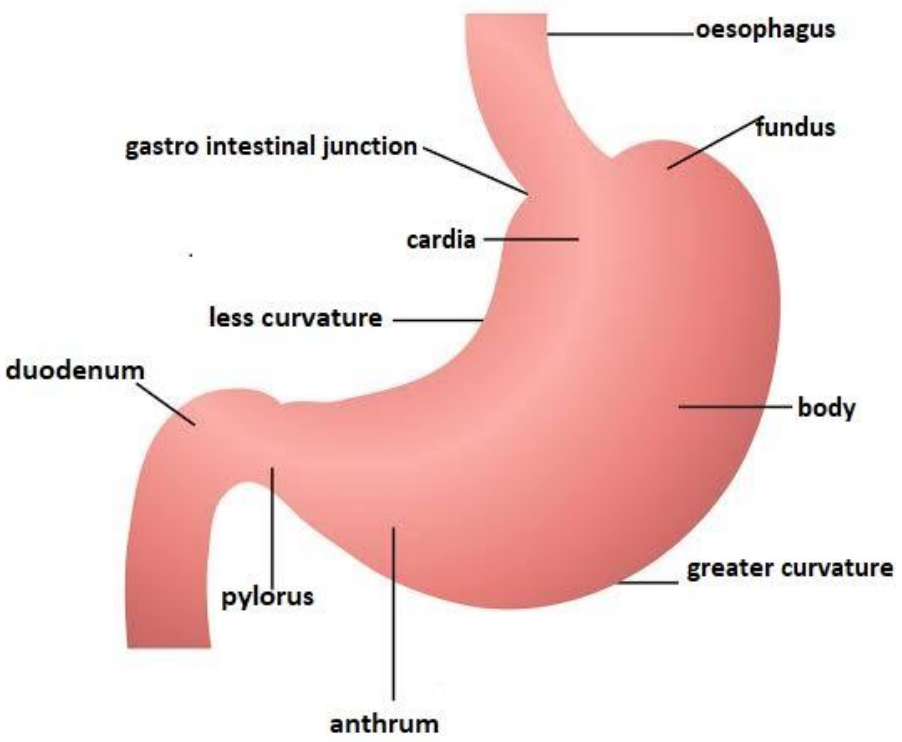

ANATOMY OF STOMACH

Fig. 1: Anatomy of stomach

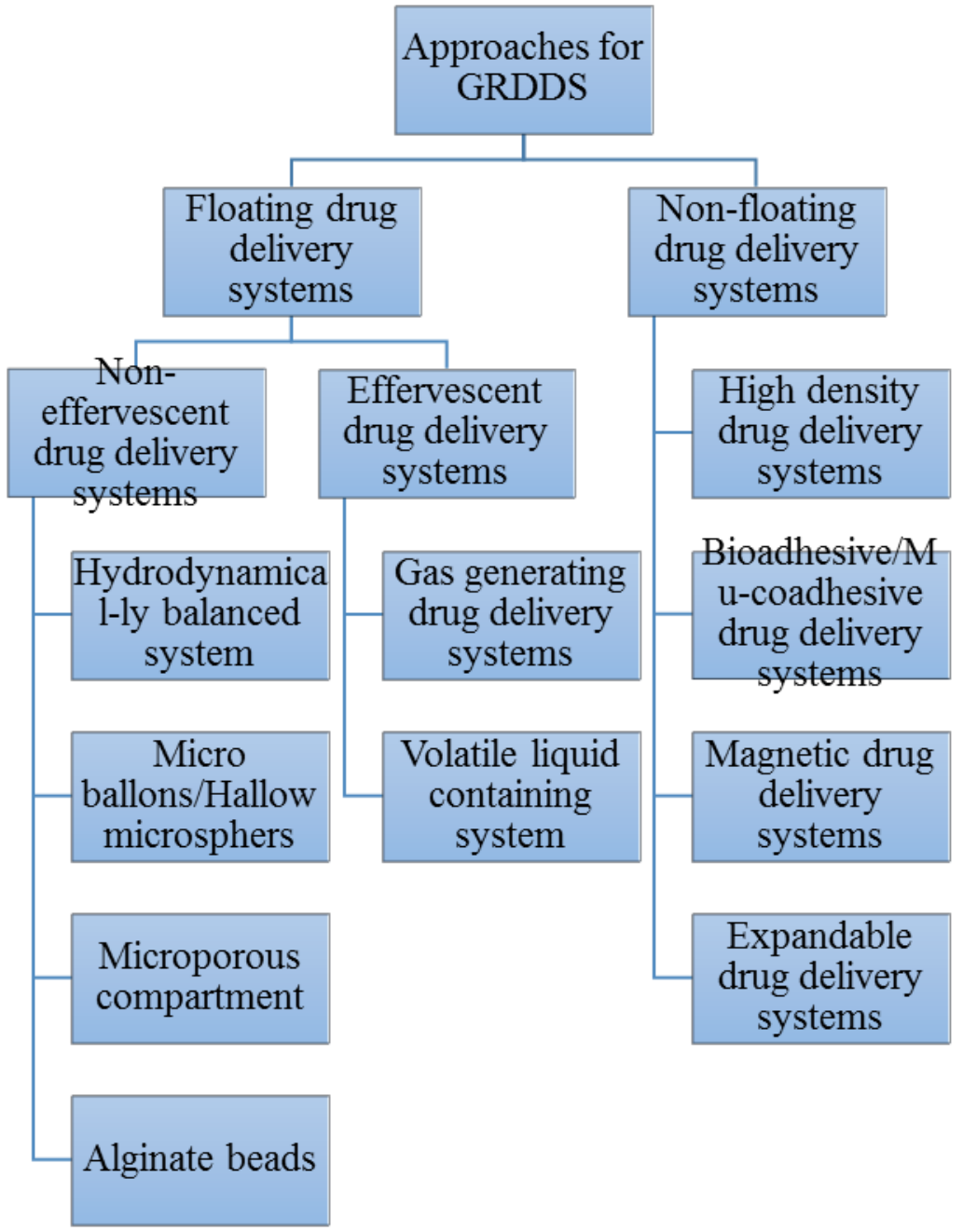


Fig. 2: Approaches for GRDDS

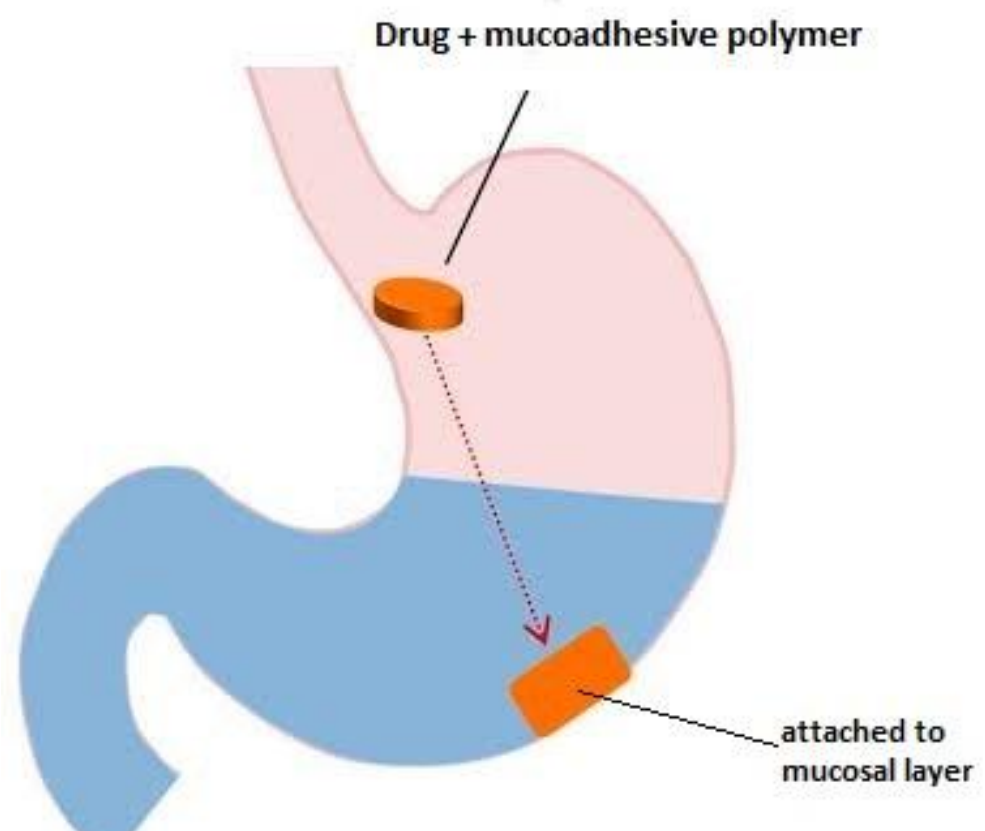

Fig. 3: Mucoadhesive drug delivery system

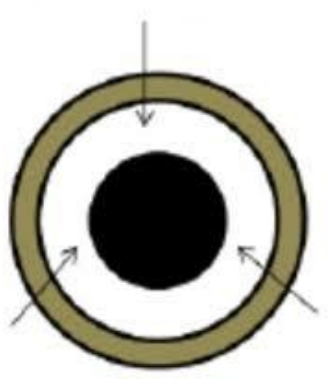

water penetration

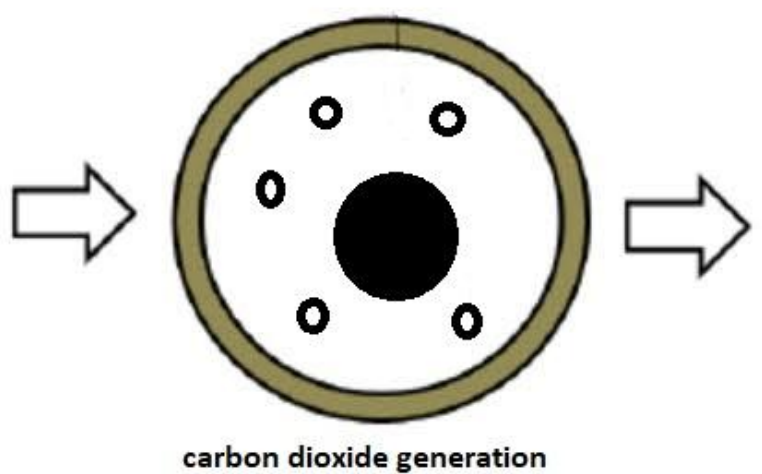

carbon dioxide generation

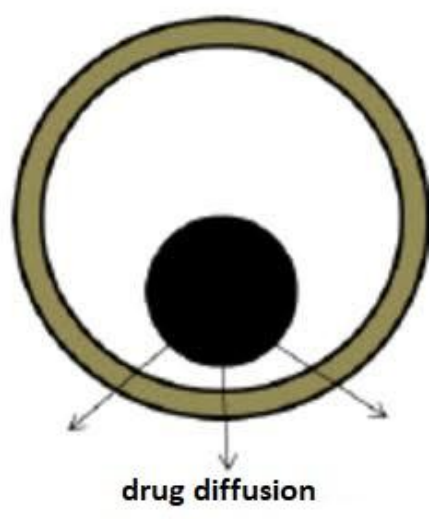

drug diffusion

Fig. 4: Effervescent drug delivery system

Table 1: Drugs used in formulation of GRDDS

\begin{tabular}{|c|c|c|}
\hline S.NO & Dosage form & Drugs \\
\hline 1 & Floating tablets & $\begin{array}{r}\text { Acetaminophen, Acetylsalicylic acid, Ampicillin, Amoxicillin trihydrate, Atenolol, } \\
\text { Captopril, Cinnerzine, Chlorpheniramine maleate, Ciprofloxacin, Diltiazem, } \\
\text { Fluorouracil, Isosorbide dintrate, Isosibide mononitrate, P-Aminobenzoic acid } \\
\text { (PABA), Prednisolone, Nimodipine, Sotalol, Theophyline,Verapamill. }\end{array}$ \\
\hline 2 & Floating capsule & $\begin{array}{r}\text { Chlordiazepoxide HCl, Diazepam, Furosemide, L-DOPA, Benserazide, } \\
\text { Nicardipine, Misoprostol, Propranolol, Pepstain. }\end{array}$ \\
\hline 3 & Floating microcapsule & Aspirin, Griseofulvin, P-Nitro Aniline, Ibuprofen, Terfenadine, Tranilast. \\
\hline 4 & Floating granules & Diclofenac sodium, Indomethacin, Prednisolone. \\
\hline $\mathbf{5}$ & Powders & Several basic drugs. \\
\hline
\end{tabular}


Table 2: Commercially available marketed products

\begin{tabular}{|c|c|c|c|c|}
\hline Brand Name & Drugs & Dosage Forms & Dose & Company \\
\hline Cifran O.D & Ciprofloxacin & Tablet & $500 \mathrm{mg}$ and $1 \mathrm{gm}$ & Ranbaxy, India \\
\hline Liquid Gavison & $\begin{array}{l}\text { Al hydroxide and } \mathrm{Mg} \\
\text { carbonate }\end{array}$ & Liquid & $\begin{array}{c}\text { 95mg and } 358 \text { mg } \\
\text { respectively }\end{array}$ & Glaxo smith kline, India \\
\hline Madopar & Levodopa and Benserazide & Capsule & $\begin{array}{c}100 \mathrm{mg} \text { and } 25 \mathrm{mg} \\
\text { respectively }\end{array}$ & Roche products, USA \\
\hline Glumetza & Metformin hydrochloride & Tablet & $500 \mathrm{mg}$ and $1000 \mathrm{mg}$ & Depomed, Canada \\
\hline Valrelease & Diazepam & Capsule & $15 \mathrm{mg}$ & Hoffmann -laroche, USA \\
\hline Topalkan & $\begin{array}{l}\text { Aluminium } 7 \& \text { agnesium } \\
\text { antacids }\end{array}$ & Liquid alginate & 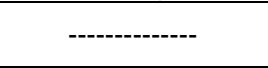 & Pierre fabre drug, France \\
\hline Cyotec & Misoprostal & Bilayer capsule & $100 \mathrm{mcg} / 200 \mathrm{mcg}$ & Pharmacia, USA \\
\hline Conviron & Ferrous sulphate & Colloidal gel & ---------------- & Ranbaxy, India \\
\hline Oflin OD & Ofloxacin & Tablet & $400 \mathrm{mg}$ & Ranbaxy, India \\
\hline
\end{tabular}

\section{REFERENCES}

1. Chawla G, Gupta P, Koradia V and Bansal AK. Gastroretension: A means to address regional variability in intestinal drug absorption. Pharmaceutical Technology. 2003;27:50-68.

2. Garg Re and Gupta GD. Progress in controlled gastro retentive delivery systems. Topical Journal of Pharmaceutical Research. 2008;7(3):1055-1066.

3. Yadav M, Sharma P, Chaudhary V and Srivastava B. Gastro retentive drug delivery system: a promising approach. Indo American Journal of Pharmaceutical Research. 2016;6(4):5225-5235.

4. Bardonnet PL, Faivre $\mathrm{V}$, Pugh WJ, Piffaretti JC and Falson Fir. Gastro retentive dosage forms: Overview and special case of Helicobacter pylori. J Control Release. 2006;111( 1-2):1 -18.

5. Patil JM, Hirlekar RS, Gide PS and Kadam VJ. Trends in floating drug delivery systems. Journal of Scientific and Industrial Research. 2006;65(1):11-21.

6. Fujimori J, Machida $Y$, Tanaka $S$ and Nagai T. Effect of magnetically controlled gastric residence of sustained release tablets on bioavailability of acetaminophen. International Journal of Pharmaceutics. 1995;119: 47-55.

7. Klausner EA, Lavy E, Friedman M and Hoffmann A. Expandable gastroretentive dosage forms. Journal of Controlled drug Release. 2003;90:143-162.

8. Thapa $P$ and Jeong $S$. effects of formulation and process variables on gastroretentive floating tablets with a high- dose soluble drug and experimental design approach. Pharmaceutics. 2018;10:1-25.
9. Gerard J Tortora and Bryan Derrickson. The digestive system: Stomach- Anatomy of the stomach. Anatomy and Physiology. Edited by Wiley. 2015; Indian Edition: 808.

10. Anne Waugh and Allison Grant. The digestive system: Stomach-Functions of stomach. Ross ans Wilson anatomy and physiology in health and illness. Edited by Elsiver Publications. 2014; $12^{\text {th }}$ Edition: 301.

11. Pandey A, Kumar G, Kothiyal $P$ and Barshiliya Y. Review on current approches in gastroretentive drug delivery system. Asian Journal of Pharmacy and Medical Science. 2012; 2(4):60-77.

12. Vyas SP. Controlled drug delivery: Concept and Advances. Vallabh Prakashan. 2006;196-217.

13. Joseph R. Controlled drug delivery fundamentals and application. Revised and Expanded Marcell. Dekker Inc. $2^{\text {nd }}$ edition. New York, 2009.

14. Khosla R and Davis SS. The effect of tablet size on the gastric emptying of non-disintegrating International Journal of Pharmaceutics. 1990;69:R9- R11.

15. Deshpandae AA, Rhodes CT, Shah $\mathrm{NH}$ and Malick AW. Controlledrelease drug delivery systems for prolonged gastric residence. An overview. Drug delivery Indian Pharmaceutics, 1996;22:531-539.

16. Abrahamsson $B$, Alpsten $M$, Hugosson M, Jonsson UE, Sundgren $M$, Svenheden $A$ and Tolli J. Absorption, gastrointestinal transit, and tablet erosin of felodipine extended release (ER) tablets.

Pharmaceutical Research.1993;10:709.

17. Oth $\mathrm{M}$, Franz $\mathrm{M}$, Timmermans $\mathrm{J}$ and Moes AJ. The bilayer floating capsule: A Stomach directed drug delivery 
system for misoprostol. Pharmaceutical research.1992;9:298.

18. Hermansson $G$ and Sivertsson $R$. Gender- related difference $s$ in gastric emptying rate of solid meals, Digestive Diseases and sciences. 1996;41(10):1994-1998.

19. Kaus LC, Fell JT, Sharma $H$ and Taylor DC. Gastric emptying and intestinal transit of non-disintegrating capsules- the influence of metaclopramide. International Journal of pharmaceutics.1984;22(1):99-103.

20. Arrora S, Ali J, Khar RK and Baboota S. Floating drug delivery system: A review. AAPSE Pharma Science Technology. 2005;6(3):372-390.

21. Chawla G, Gupta $P$ and Bansal AK. Gastroretentive drug delivery system. In Jain NK. Editor. Progress in Controlled and novel drug delivery system CBS Publication and Distributors. New Delhi. 2004;76-97.

22. Clarke GM, Newton JM and Short MD. Gastrointestinal transit of pellets of differing size and density. International journal 1993;100(13):81-92.

23. Moes AJ. Gastric retention system for oral drug delivery. Business briefing. Pharmatech. 2003;157-159.

24. Misra SK. Gastrointestinal targetting drug delivery system: A Review. Journal of Pharmacy Research. 2011;4(8):2751- 2754.

25. Rao BP, Kottan NA, Snehith VH and Ramesh C. Development of gastroretentive drug delivery system of Cephalexin by using factorial design. ARE Pharmaceutical. 2009;50: 8.

26. Sheth PR and Tossounian J. The hydrodyanamically balanced system. A novel drug delivery system for oral use. Drug delivery Indian Pharmaceutics. 2010;3(1):819-833.

27. Prajapati VD, Jani GK, Khutliwala TA and Zala BS. Raft forming system - An upcoming approach of gastroretentive drug delivery system. Journal of Control Release. 2013;168: 151-165.

28. Prinderre P, Sauzet $C$ and Fuxen C. Advances in Gastro-retentive drugdelivery systems. Expert Opin. Drug delivery. 2011;8:1189-1203.

29. Chen YC, Ho HO, Lee TY and Sheu MT. Physical Characterization and sustained release profiling of gastroretentive drug delivery systems with improved floating and swelling capabilities. International Journal of pharmaceutics. 2013;441:162-169.

30. Chen J, Blevins WE, Park $\mathrm{H}$ and Park K. Gastric retention properties of superporous hydrogel composities. Journal of Control release. 2000;64:39-51.

31. Kashyap N, Viswanad B, Sharma G, Bhardwaj V, Ramarao $P$ and Kumar MR. Design and evaluation of biodegradable, biosensitive in situation gelling system for pulsatile delivery of insulin. Biomaterials. 2007;28: 20512060.

32. Verma S, Nagpal K, Singh S and Mishra D. Unfolding type gastroretentive film of cinnarzine based on ethyl cellulose and hydroxypropyl methylcellulose. Int J Biol Macromol. 2014;64: 347-352.

33. Anand V, Kandarapu R and Garg S. Ion exchange resins: carrying drug delivary forward. Drug discov. Today. 2001;6:905-914.

34. Torres D, Boado L, Blanco D and VilaJato JL. comparision between aqueous and non-aqueous solvent evaporation methods for microencapsulation of drug-resin complexes. Int J pharm.1998;173:171182.

35. Inukai K, Takiyama K, Noguchi S, Iwao $Y$ and Itai $S$. Effect of gel formation on the dissolution behaviour of clarithromycin tablets. Int $\mathrm{J}$ Pharm. 2017;521:33-39.

36. Tadros MI. Controlled-release effervescent floating matrix tablets of ciprofloxacin hydrochloride. Development, optimization and in vitro and in vivo evaluation in healthy human volunteers. Eur J Pharm Biopharm. 2010;74:332-339.

37. El-said IA, Aboelwafa AA, Khalil RM and El Gazayerly ON. Baclofen novel gastroretentive extended release gellan gum superporous hydrogel hybrid system: Invitro-invivo evaluation. Drug Deliv.2016;23:101112.

38. Chandrashekar $\mathrm{G}$ and Udupa $\mathrm{N}$. Biodegradable injectable implant systems for long term drug delivary using poly (Lactic-co-glycolic) Acid copolymers. J Pharm Pharmacol.1996;48:669-674. 